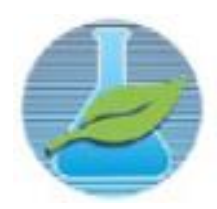

\title{
LOGÍSTICA REVERSA APLICADA AO DESCARTE CORRETO DO LIXO ELETRÔNICO
}

\author{
Ariana Porto da Conceição, Carlos Antônio Gonçalves Rosado, Dyennerson Franca Silva, \\ Shayder Mendes \\ Instituto Federal de Educação, Ciência e Tecnologia de Minas Gerais \\ Avenida Minas Gerais, 5189 - Ouro Verde - 35-057-760 - Governador Valadares - MG - \\ ariana-porto@hotmail.com, carlos.rosado@ifmg.edu.br, dyennerson.ifmgep@gmail.com, \\ shayderm@gmail.com
}

\section{INTRODUÇÃ̃O}

Segundo um estudo da Associação de empresas da indústria Móvel (GSMA) e da Universidade das Nações Unidas em 2014, o Brasil produzia 36,16\% do lixo eletrônico da América Latina. Nos últimos 11 anos, o aumento da geração de lixo no país foi muito maior do que o crescimento populacional. De 2003 a 2014, a geração de lixo cresceu 29\%, enquanto a taxa de crescimento populacional foi de $6 \%$. A parcela deste lixo depositado em locais considerados inadequados (lixões e aterros controlados), em 2014, era de 41,6\% (Lenharo, 2015). O descarte incorreto deste lixo gera sérios problemas ambientais, além do grande volume de materiais que demoram muito a se decompor, sua composição possui metais altamente tóxicos. Desta maneira o lixo eletrônico vem trazendo uma preocupação cada vez maior para aqueles que se preocupam com o bem-estar do planeta. A acelerada produção e o consumo demasiado de eletroeletrônicos e eletrodomésticos, faz com que o volume destes materiais descartados indevidamente cada vem mais rápido, assim diminuindo o espaço de armazenamento e aumentando o impacto ambiental (Andrade, 2002).

Como descartar uma quantidade cada vez maior de lixo eletrônico? A relevância da logística reversa neste cenário assume papel primordial, entendida como o processo de planejamento, implementação e controle da eficiência, do custo efetivo do fluxo de matérias-primas, estoques em processo, produtos acabados e informações relacionadas do ponto de consumo ao ponto de origem com objetivo de reagregar valor ou efetuar o descarte adequadamente (Rogers \& Tibben-Lembke, 1999).

\subsection{OBJETIVO GERAL}

O presente artigo visa contribuir com a conscientização sobre os impactos do lixo eletrônico, propondo uma visão de forma que a logística reversa pode ser aplicada no descarte correto deste lixo e possível geração de renda a população, criando uma cadeia reversa para o lixo eletrônico de Governador Valadares (MG).

\subsection{JUSTIFICATIVA}

A realização de um projeto na cidade de Governador Valadares (MG) sobre descarte adequado do lixo eletrônico, utilizando a ferramenta logística reversa nos procedimentos na cadeia reversa é de fundamental importância devido a este tipo de lixo possui agentes nocivos e que após o contato com o solo, mananciais ou rios pode causar danos de tal modo que podem ser irreversíveis a saúde humana, animal e ao meio ambiente. Os materiais tais como pilhas, baterias, computadores, materiais eletroeletrônicos, celulares dentre outros podem ser destinados para um local adequado e 
após empresas especializadas reciclarem este material da forma correta, os mesmos poderão retornar a sociedade e consequentemente reduzir os problemas acima apresentados.

\section{METODOLOGIA}

O desenvolvimento deste trabalho foi realizado primeiramente através da revisão bibliográfica aplicada ao estudo da logística reversa no ramo do lixo eletrônico. Para o desenvolvimento deste trabalho primeiramente foram realizadas pesquisas e coleta de dados, afim que encontrar informações que poderão ser utilizados para a elaboração.

Concluída esta análise foi constatado que atualmente Governador Valadares (MG) não possui local para o descarte de lixo comum tão pouco para o descarte de lixo eletrônico. Os lixos comuns são transportados via modal rodoviário para Ipatinga (MG) localizada a cerca de $105 \mathrm{~km}$ de distância, onde lá são depositados em aterro sanitário controlado. Portanto é de fundamental importância para o meio ambiente e sociedade, a criação de um local para o descarte correto do lixo eletrônico em Governador Valadares (MG). A colaboração de parceiros se faz necessária, visto que não é uma tarefa fácil, a princípio o foco será a criação do projeto, que irá armazenar o material coletado e posteriormente transporta-lo até uma empresa especializada em Belo Horizonte (MG).

\section{A LOGÍSTICA REVERSA}

A Logística reversa é definida segundo a LEI No 12.305, DE 2 DE AGOSTO DE 2010, Art. 3o inciso XII como: instrumento de desenvolvimento econômico e social caracterizado por um conjunto de ações, procedimentos e meios destinados a viabilizar a coleta e a restituição dos resíduos sólidos ao setor empresarial, para reaproveitamento, em seu ciclo ou em outros ciclos produtivos, ou outra destinação final ambientalmente adequada. Para Leite (2003) a logística reversa como a área da logística empresarial que planeja, opera e controla o fluxo e as informações logísticas correspondentes do retorno dos bens de pós-venda e de pós-consumo ao ciclo de negócios ou ao ciclo produtivo, por meio dos canais de distribuição reversos, agregando-lhes valor de diversas naturezas: econômico, ecológico, legal, logístico, de imagem corporativa, entre outros. Desta forma, a logística reversa tem como objetivo, segundo Leite (2003), tornar possível o retorno dos bens ou de seus materiais constituintes ao ciclo produtivo ou de negócios, agregando valor econômico, ecológico, legal e de localização

O reaproveitamento de materiais e a economia com embalagens retornáveis têm trazido ganhos que estimulam cada vez mais iniciativas e esforços para implantação da logística reversa, visando a eficiente recuperação de produtos, segundo Rogers e Tibben Lembke (1998).

\section{O LIXO ELETRÔNICO COMO GERADOR DE RENDA}

De acordo com um relatório divulgado pela ONU para o Meio Ambiente (PNUMA), até 90\% do lixo eletrônico do mundo é comercializado ilegalmente ou jogado no lixo a cada ano, um valor estimado em 19 bilhões de dólares. A Organização Internacional de Polícia Criminal (INTERPOL) estima que o preço de uma tonelada de lixo eletrônico gira em torno de 500 dólares. Seguindo esse cálculo, estima-se que o valor do lixo eletrônico não registrado e informalmente manuseado, incluindo os que são comercializados ilegalmente e despejados, encontra-se entre 12,5 a 18,8 bilhões de dólares por ano. O mercado global de resíduos, desde a coleta até a reciclagem, é estimado em 410 bilhões de dólares por ano, gerando emprego e renda.

Uma estimativa publicada na Revista Guia Exame (2010) mostrou que a venda de equipamentos eletrônicos no Brasil é crescente, em 2004 foi estimado a venda de 28,9 milhões de celulares, em 2010 esses números chegaram em torno de 47,6 milhões de unidades. Levando em consideração a indústria de eletrônicos que é um mercado que só tende a se expandir aumentando a geração de lixo eletrônico, a implementação de uma cadeia reversa em prol da coleta do lixo eletrônico em Governador-Valadares seria promissora, tendo em vista que é um mercado inexistente na cidade e como consequência traria a criação de emprego para a mesma. 


\section{O LIXO ELETRÔNICO COMO INCLUSÃO DIGITAL}

A inclusão digital é um direito a partir do momento que, por suas características, ela não é somente uma necessidade, mas um valor que acrescenta ao ser humano potencialidades e maneiras de se realizar como tal, realçando e ativando outros direitos inerentes a sua condição, como a liberdade, a igualdade e a dignidade (Gonçalves, 2012), além do direito à cidadania.

\section{EDUCAÇÃo DA POPULAÇÃo QUANTO AO DESCARTE}

Para que a ideia do descarte correto ocorra é necessário educar a população para o fazê-lo. Pois muitos não possuem acesso a informação de como é feito o descarte, quanto as formas, locais de destinação, para que serve isso. Segundo o CONAMA, a Educação Ambiental é definida como "um processo de formação e informação orientada para o desenvolvimento da consciência crítica sobre as questões ambientais, e de atividades que levem a participação da comunidade na preservação do equilíbrio ambiental”.

\section{CONSIDERAÇÕES FINAIS}

A preservação do meio ambiente se faz cada vez mais necessária, pois quanto mais preservamos os recursos naturais, mais tempo garantimos nossa sobrevivência, de gerações futuras e a utilização dos mesmos insumos para confecção de outros materiais. A logística reversa vem como fator integrante deste ciclo, devolvendo a sociedade produtos descartados e sem mais utilidades em produtos reciclados e a ponto de ser reutilizado, podendo ser uma fonte de trabalho e consequentemente de renda. Deste modo com o desejo de diminuir o impacto ambiental e conscientizar a população do descarte adequado do lixo eletrônico gerado em Governador Valadares (MG), o presente artigo servira de base para a criação de um projeto, que visa a implementação de uma coleta de lixo eletrônico na cidade.

\section{REFERÊNCIAS}

ANDRADE, R. "Caracterização e Classificação de Placas de Circuito Impresso de Computadores como Resíduos Sólidos". Campinas, 2002. Tese (Faculdade de Engenharia Mecânica). Universidade Estadual de Campinas.

CELERE, M. S. et al. "Metais presentes no chorume coletado no aterro sanitário de Ribeirão Preto, São Paulo, Brasil, e sua relevância para saúde pública". Cadernos de Saúde Pública, vol. 23, nº 4, Rio de Janeiro, Abr. de 2007.

G1, 2015. "Mesmo com política de resíduos, 41,6\% do lixo tem destino inadequado". Acesso em: 22 Set. 2016. Disponível em: <http://g1.globo.com/natureza/noticia/2015/07/mesmo-com-politica-deresiduos-416-do-lixo-tem-destino-inadequado.html.>

GUIA EXAME DE SUSTENTABILIDADE, 2010.

LEITE, P. R. "Logística Reversa - Meio ambiente e Competitividade”. São Paulo: Prentice Hall, 2003.

PLANALTO, 2010. "Mesmo com política de resíduos, 41,6\% do lixo tem destino inadequado". Acesso em: 10 Out. 2016. Disponível em: http://www.planalto.gov.br/ccivil_03/_ato20072010/2010/lei/112305.htm.>

ROGERS, D. S.; TIBBEN-LEMBKE, R. "Going Backwards: Reverse Logistics Trends and Practices" Reno: Reverse Logistics Executive Council, 1998.

SILVA, D. R.; MARQUES. D. A.; DONADEL S. M. V. "Inclusão digital e Direitos Humanos: desafio à educação contemporânea". Acesso em 15 out. 2016. Disponível em:< coral.ufsm.br/educomsul/2013/com/gt2/12.pdf >

UNEP, 2015. "Waste crime - waste risks gaps in meeting the global waste challenge". Acesso em: 22 Set. 2016. Disponível em: <http://www.unep.org/environmentalgovernance /Portals/8/documents/rra-wastecrime.pdf. > 